\title{
Kontribusi Dukungan Keluarga dan Teman Bergaul Terhadap Indeks Prestasi Kumulatif Mahasiswa Dengan Memperhatikan Intensitas Belajar
}

\author{
Alia Lestari, Nur Ma'wiyah, Muhammad Ihsan \\ Prodi Tadrid Matematika, FTIK, Institut Agama Islam Negeri Palopo \\ Jl. Agatis, Kel. Balandai, Kota Palopo, Sulawesi Selatan, 91914 \\ Email:alialestari@iainpalopo.ac.id
}

Article History:

Received: 17-09-2019; Received in Revised: 17-03-2020; Accepted: 29-03-2020

\begin{abstract}
Several factors usually affect student's Grade Point Average (GPA), including family support, associate friends and learning intensity. This study aims to determine whether there is an indirect effect of family and friends support associating with the cumulative achievement index of students through the excitement of learning as an intervening variable. This type of research is ex-post facto with a population of 278 students of the 2015-2017 Mathematics Tadris Study Program. We used a Proportionate Stratified Random Sampling technique to select a sample of 164 students. We obtained data through questionnaires and documentation and then analyzed using path analysis. The results showed that there was an indirect influence of family and friends support associating with student GPA through the intensity of learning as an intervening variable.
\end{abstract}

Keywords: Path Analysis; Family Support; Learning Intensity; Grade Point Average; Associate Friends.

\begin{abstract}
Abstrak
Indeks Prestasi Kumulatif (IPK) mahasiswa biasanya dipengaruhi oleh beberapa faktor, diantaranya adalah dukungan keluarga, teman bergaul dan intensitas belajar. Penelitian ini bertujuan untuk mengetahui apakah ada pengaruh tidak langsung dukungan keluarga dan teman bergaul terhadap indeks prestasi komulatif mahasiswa melalui intensitas belajar sebagai variabel intervening. Jenis penelitian ini adalah ex-post facto dengan populasi sebanyak 278 mahasiswa Program Studi Tadris Matematika angkatan 2015-2017. Pengambilan sampel sebanyak 164 mahasiswa dilakukan dengan teknik Probability Sampling tipe Proportionate Stratified Random Sampling. Data diperoleh melalui kuisioner dan dokumentasi kemudian dianalisis menggunakan analisis jalur. Hasil penelitian menunjukkan bahwa ada pengaruh tidak langsung dukungan keluarga dan teman bergaul terhadap IPK mahasiswa melalui intensitas belajar sebagai variabel interverning.
\end{abstract}

Kata Kunci: Analisis Jalur; Dukungan Keluarga; Indeks Prestasi Kumulatif;, Intensitas Belajar, Teman Bergaul. 


\section{Pendahuluan}

Indeks Prestasi Kumulatif (IPK) merupakan suatu nilai yang menunjukkan prestasi yang dicapai oleh mahasiswa secara kumulatif, dihitung mulai dari semester satu hingga semester terakhir. Baik tidaknya prestasi seorang mahasiswa dapat diukur dari tinggi rendahnya IPK mahasiswa tersebut. Kadir Pepe membuktikan bahwa mahasiswa dengan IPK tinggi memiliki keahlian yang lebih baik dari mahasiswa dengan IPK rendah¹. IPK juga seringkali menjadi salah satu kriteria penerimaan pegawai, baik itu karyawan di perusahaan swasta, maupun di pemerintahan, biasanya mensyaratkan nilai IPK tertentu.

Beberapa penelitian telah mengkaji faktor-faktor yang dapat mempengaruhi IPK mahasiswa. Putriaji Hendikawati menemukan bahwa faktor-faktor yang berpengaruh terhadap IPK mahasiswa adalah faktor manajemen diri, faktor lingkungan sekitar, faktor kondisi eksternal, faktor kondisi fisik dan faktor olahraga ${ }^{2}$. Karyanus dkk menunjukkan bahwa IPK mahasiswa matematika Universitas Sumatera Utara dipengaruhi oleh faktor lingkungan dan pengawasan orang tua, faktor kondisi finansial dan motivasi belajar, faktor kualitas belajar dan pembagian waktu belajar, dan faktor kualitas pengajaran dosen dan kesehatan mahasiswa ${ }^{3}$.

Pada penelitian lain disebutkan bahwa anak akan menerima pengaruh dari keluarga berupa: cara orang tua mendidik anak, relasi antara anggota keluarga, suasana rumah tangga dan keadaan ekonomi keluarga ${ }^{45}$. Faktorfaktor tersebut apabila dapat dijalankan sesuai dengan fungsi dan peranannya masing-masing dengan baik, kemungkinan dapat menciptakan situasi dan kondisi yang dapat mendorong anak untuk lebih giat dan disiplin dalam belajar67. Selain lingkungan keluarga, faktor lain yang dapat memengaruhi prestasi belajar adalah intensitas belajar. Berbeda dengan

${ }^{1}$ Kadir Pepe, "A Research of the Relationship Between Study Skills of Students and Their Gpa," Procedia-Social and Behavioral Sciences 47 (2012): 1048-1057.

2 Putriaji Hendikawati, "Analisis Faktor Yang Mempengaruhi Indeks Prestasi Mahasiswa," Kreano, Jurnal Matematika Kreatif-Inovatif2, no. 1 (2011): 27-35.

3 Karyanus Daely, Ujian Sinulingga, and Asima Manurung, "Analisis Statistik FaktorFaktor Yang Mempengaruhi Indeks Prestasi Mahasiswa," Saintia Matematika 1, no. 5 (2013): 483-494.

4 Slameto, Belajar Dan Faktor Yang Mempengaruhinya (Jakarta: Rineka Cipta, 2010).

5 Xavier Oriol et al., "Comparing Family, Friends and Satisfaction with School Experience as Predictors of Swb in Children Who Have and Have Not Made the Transition to Middle School in Different Countries," Children and Youth Services Review 80 (2017): 149156.

${ }^{6}$ Debra Siegel Levine et al., "Family and Friendship Informal Support Networks and Social Anxiety Disorder Among African Americans and Black Caribbeans," Social Psychiatry and Psychiatric Epidemiology 50, no. 7 (2015): 1121-1133.

7 Arthur E. Mesas et al., "Individuals' Perceptions of Social Support from Family and Friends Are Associated with Lower Risk of Sleep Complaints and Short Sleep Duration," Sleep Health 6, no. 1 (2020): 110-116. 
lingkungan keluarga, intensitas belajar merupakan faktor yang berasal dari dalam diri yang berpengaruh secara langsung terhadap peningkatan prestasi ${ }^{8}$.

Intensitas belajar adalah realitas dari motivasi dalam rangka mencapai tujuan yang diharapkan yaitu peningkatan prestasi, sebab seseorang melakukan usaha dengan penuh semangat karena adanya motivasi sebagai pendorong pencapaian ${ }^{9}$. Artinya seseorang yang memiliki intensitas belajar yang tinggi maka akan cenderung mendapatkan hasil belajar yang baik. Sebaliknya, seseorang yang kurang intensitas belajarnya akan cenderung memiliki hasil belajar yang kurang juga. Berdasarkan hal tersebut, indikator intensitas belajar yaitu adanya keteraturan belajar, kedisiplinan belajar serta konsentrasi belajar.

Teman bergaul yang dimiliki oleh seorang anak dapat merupakan sahabat maupun bukan sahabat. Namun sahabat bagi seorang anak pastilah seorang teman bergaul bagi anak. Fungsi persahabatan, menurut Gottman dan Parker dalam Agoes Dariyo ${ }^{10}$, yaitu (1) sebagai teman, (2) sebagai orang yang merasakan hal yang positif, (3) memberikan dukungan secara fisik, (4) memberikan dukungan ego, (5) sebagai pembanding social dan (6) memberikan suasana keakraban. Interaksi dengan teman bergaul yang kurang baik juga dapat menimbulkan dampak yang kurang baik pula bagi hasil belajar mahasiswa. Hal tersebut tentunya akan mempengaruhi intensitas belajar mahasiswa baik di kampus maupun di rumah. Salomina Patty dan kawan-kawan menyatakan bahwa ada hubungan dukungan sosial teman sebaya dengan prestasi belajar ${ }^{11}$.

Berdasarkan hal tersebut, indikator teman bergaul dalam penelitian ini yaitu kerjasama, persaingan, pertentangan, penyesuaian/ akomodasi, serta perpaduan/ asimilasi dengan teman bergaul. Sedangkan indikator dukungan keluarga dalam penelitian ini yaitu cara orang tua mendidik, relasi antar anggota keluarga, suasana rumah, serta keadaan ekonomi keluarga.

Artikel ini mencoba melakukan suatu analisis jalur kontribusi dukungan keluarga dan teman bergaul terhadap indeks prestasi kumulatif mahasiswa dengan memperhatikan intensitas belajarnya. Dari sini akan

8 Putri Sri Wahyuni, "Pengaruh Intensitas Belajar, Kemampuan Berpikir Kritis Dan Cara Belajar Terhadap Prestasi Akademik Mahasiswa Pada Program Studi Pendidikan Ekonomi STKIP PGRI Sumatera Barat." (PhD Thesis, STKIP PGRI SUMATERA BARAT, 2016).

9 Melda, "Pengaruh Media Massa Terhadap Intensitas Belajar Matematika Di Rumah Pada Siswa Kelas XI IPS MAN Palopo." (Skripsi, Palopo, IAIN Palopo, 2015).

10 Agoes Dariyo, "Psikologi Perkembangan Remaja," Bogor: Ghalia Indonesia, 2004.

11 Salomina Patty, Sutarto Wijono, and Adi Setiawan, "Hubungan Dukungan Sosial Teman Sebaya, Kontrol Diri, Dan Jenis Kelamin Dengan Prestasi Belajar Siswa Di SMA Kristen YPKPM Ambon," PSIKODIMENSIA 15 (June 20, 2017): 204, https://doi.org/10.24167/psiko.v15i2.989. 
diperoleh gambaran tentang pengaruh keluarga dan teman bergaul terhadap indeks prestasi kumulatif mahasiswa.

\section{Metode}

Populasi dalam penelitian ini adalah seluruh mahasiswa Tadris Matematika Institut Agama Islam Negeri (IAIN) Palopo, sebanyak 278 mahasiswa/i yang tersebar pada 3 angkatan yaitu 2015 sampai dengan 2017. Metode pengambilan sampel yang digunakan untuk memperoleh sampel yaitu teknik Probability Sampling dengan tipe Proportionate Stratified Random Sampling, yaitu pengambilan sampel dari anggota populasi secara acak dan berstrata secara proporsional dengan mengambil masing-masing angkatan 2015-2017. Jumlah sampel yang terpilih sebanyak 164 mahasiswa dari total 278 mahasiswa.

Instrumen yang digunakan adalah angket yang sebelumnya telah diuji validitas dan reliabilitasnya. Teknik analisis yang dilakukan adalah statistik deskriptif, diperlukan untuk mendeskripsikan data dari variabel-variabel penelitian yang diajukan. Untuk teknik analisis deskriptif meliputi mean, median, modus, standar deviasi,dan tabel distribusi frekuensi. Selanjutnya digunakan analisis inferensial untuk menganalisis dan memvalidasi model yang diusulkan serta untuk melakukan pengujian hipotesis. Statistika inferensial yang digunakan adalah teknik analisis jalur dengan menggunakan paket program IBM SPSS Statistic 22 dan IBM SPSS AMOS (Analysis of Moment Structure) 22.

\section{Hasil dan Diskusi}

Berdasarkan hasil analisis statistika inferensial menggunakan program AMOS diperoleh hasil sebagai berikut:

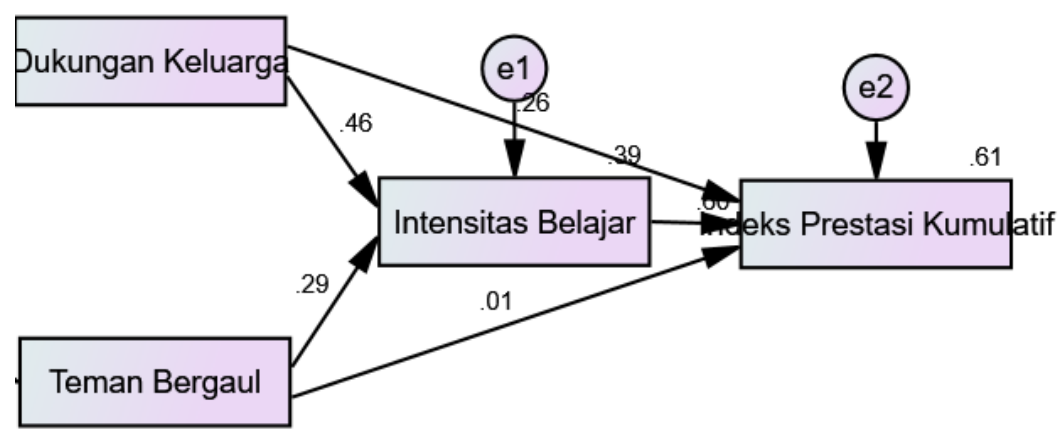

Gambar 1. Path Diagram 

Maret-2020, Vol.8, No.1, hal.51-60

Tabel. 1 Estimasi parameter Regression Weights Model Tahap Akhir

\begin{tabular}{|c|c|c|c|c|c|c|}
\hline & Path & & Estimate & S.E. & C.R. & $P$ \\
\hline $\bar{Y}$ & $<---$ & $\mathrm{X} 1$ & .263 & .038 & 6.962 & *** \\
\hline$Y$ & $<--$ & $\mathrm{X} 2$ & .105 & .024 & 4.378 & $* * *$ \\
\hline $\mathrm{Z}$ & $<---$ & $Y$ & .056 & .006 & 9.352 & $* * *$ \\
\hline $\mathrm{Z}$ & $<--$ & $\mathrm{X} 1$ & .014 & .003 & 4.280 & $* * *$ \\
\hline $\mathrm{Z}$ & $<---$ & $\mathrm{X} 2$ & .000 & .002 & .132 & .895 \\
\hline
\end{tabular}

Tabel. 2. Hasil Standardized Regression Weights

\begin{tabular}{ccccc}
\hline & Path & Estimate & Pengaruh tidak Langsung \\
\hline Y & $<---$ & X1 & .462 & .000 \\
\hline Y & $<---$ & X2 & .290 & .000 \\
\hline Z & $<---$ & Y & .598 & .000 \\
\hline Z & $<---$ & X1 & .261 & .015 \\
\hline Z & $<---$ & X2 & .007 & .006 \\
\hline
\end{tabular}

Tabel 3. Pengaruh Langsung

\begin{tabular}{cccc}
\hline & $\mathrm{X} 2$ & $\mathrm{X} 1$ & $\mathrm{Y}$ \\
\hline $\mathrm{Y}$ & .290 & .462 & .000 \\
\hline $\mathrm{Z}$ & .007 & .261 & .598 \\
\hline
\end{tabular}

Tabel. 4 Pengaruh Tidak Langsung

\begin{tabular}{cccc}
\hline & $\mathrm{X} 2$ & $\mathrm{X} 1$ & $\mathrm{Y}$ \\
\hline $\mathrm{Y}$ & .000 & .000 & .000 \\
\hline $\mathrm{Z}$ & .174 & .276 & .000 \\
\hline
\end{tabular}

Tabel. 5 Pengaruh Total

\begin{tabular}{cccc}
\hline & $\mathrm{X} 2$ & $\mathrm{X} 1$ & $\mathrm{Y}$ \\
\hline $\mathrm{Y}$ & .105 & .263 & .000 \\
\hline $\mathrm{Z}$ & .006 & .029 & .056 \\
\hline
\end{tabular}

Berdasarkan output AMOS tersebut diperoleh nilai regression weight pada Tabel 1 dan besar pengaruhnya pada Tabel 2 dapat dilihat bahwa semua variabel berpengaruh secara signifikan kecuali variabel teman bergaul. Dengan demikian uji hipotesis dapat diartikan seperti di bawah ini:

1) Ho : Dukungan Keluarga tidak berpengaruh langsung terhadap IPK Ha : Dukungan Keluarga berpengaruh langsung terhadap IPK 
Tabel 2 menunjukkan koefisien variabel dukungan keluarga sebesar 0,261 dan nilai signifikansi sebesar 0,000 < 0,05 maka Ho ditolak, artinya Dukungan Keluarga berpengaruh langsung terhadap IPK.

2) Ho : Teman Bergaul tidak berpengaruh langsung terhadap IPK

Ha : Teman Bergaul berpengaruh langsung terhadap IPK

Dari dugaan tersebut setelah di uji ternyata diperoleh koefisien variabel teman bergaul sebesar 0,007. Pengaruh teman bergaul tidak signifikan secara statisitik karena diketahui bahwa signifikansi variabel teman bergaul sebesar 0,895 > 0,05 maka Ha ditolak, artinya Teman Bergaul tidak berpengaruh langsung terhadap IPK.

3) Ho : Intensitas Belajar tidak berpengaruh langsung terhadap IPK

$\mathrm{Ha} \quad$ : Inntensitas Belajar berpengaruh langsung terhadap IPK

Pengaruh variabel intensitas belajar signifikan secara statistik karena memiliki nilai koefisien sebesar 0,598 dan nilai signifikansi sebesar 0,000< 0,05 maka Ho ditolak, artinya Intensitas Belajar berpengaruh langsung terhadap IPK.

4) $\mathrm{H}_{0} \quad$ : Dukungan keluarga tidak berpengaruh terhadap intensitas belajar.

$\mathrm{H}_{\mathrm{a}} \quad$ : Dukungan keluarga berpengaruh terhadap intensitas belajar.

Hasil pengujian membuktikan bahwa koefisien variabel dukungan keluarga terhadap intensitas belajar adalah sebesar 0,462. Pengaruh dukungan keluarga terhadap intensitas belajar signifikan secara statistik karena memiliki nilai signifikansi sebesar 0,000<0,05, maka Ho ditolak yang berarti ada pengaruh yang signifikan dari variabel dukungan keluarga terhadap intensitas belajar.

5) $\mathrm{H}_{0} \quad$ : Teman bergaul tidak berpengaruh terhadap intensitas belajar.

$\mathrm{H}_{\mathrm{a}} \quad$ : Teman bergaul berpengaruh terhadap intensitas belajar.

Berdasarkan Tabel 2 diperoleh bahwa pengaruh variabel teman bergaul terhadap intensitas belajar signifikan secara statistik karena memiliki pvalue sebesar $0,000<0,05$. Dan memiliki nilai koefisien variabel sebesar 0,290, maka dari itu Ho ditolak yang berarti ada pengaruh yang signifikan dari variabel teman bergaul terhadap variabel intensitas belajar.

Berdasarkan hasil uji hipotesis diperoleh pengujian terhadap pengaruh dukungan keluarga dengan intensitas belajar memperoleh hasil yang signifikan. Dengan nilai $p$-value sebesar 0,000 kurang dari 0,05, maka Ho ditolak. Artinya terdapat pengaruh yang signifikan antara dukungan keluarga dan teman bergaul terhadap intensitas belajar mahasiswa. Adapun besar pengaruhnya dilihat pada besar koefisiennya yaitu sebesar 0,462 atau 46,2\%. Hasil penelitian terhadap pengaruh variabel teman bergaul dengan intensitas belajar menunjukkan pengaruh yang signifikan. Setelah dilakukan uji hipotesis, diperoleh nilai $p$-value sebesar 0,000 kurang dari 0,05 dengan nilai 
koefisisen variabel sebesar 0,290 sehingga Ho ditolak. Artinya teman bergaul berpengaruh secara langsung terhadap intensitas belajar mahasiswa. Hasil penelitian ini diperkuat dengan pernyataan Slameto bahwa pengaruhpengaruh dari teman bergaul lebih cepat masuk ke dalam jiwa seseorang daripada yang kita duga. Teman bergaul yang baik akan berpengaruh baik terhadap diri seseorang begitupula sebaliknya ${ }^{12}$.

Uji hipotesis menunjukkan dukungan keluarga memiliki pengaruh langsung yang paling besar terhadap IPK dengan nilai beta sebesar 0,261 dengan nilai signifikan sebesar 0,000 $<0,05$ sehingga Ho ditolak. Artinya dukungan keluarga berpengaruh langsung terhadap IPK. Penelitian ini sejalan dengan penelitian sebelumya yaitu penelitian yang dilakukan oleh Suratno yang berkesimpulan bahwa terdapat pengaruh signifikan lingkungan keluarga terhadap prestasi belajara sebesar $14,29 \%{ }^{13}$. Hal ini didukung oleh pernyataan Tu'u bahwa pengaruh utama dan pertama bagi kehidupan, pertumbuhan dan perkembangan seseorang adalah pengaruh keluarga ${ }^{14}$. Hal ini disebabkan karena keluarga merupakan orang-orang terdekat bagi seorang anak. Banyak kesempatan dan waktu bagi seorang anak untuk berjumpa dan berinteraksi dengan keluarga. Perjumpaan dan interaksi tersebut sudah pasti besar pengaruhnya bagi hasil belajar seseorang.

Hasil penelitian ini menunjukkan bahwa teman bergaul tidak berpengaruh langsung terhadap IPK. Uji hipotesis menunjukkan teman bergaul memiliki pengaruh terhadap IPK dengan nilai beta sebesar 0,007 dengan nilai signifikan sebesar 0,895 $>0,05$ sehingga Ho diterima. Artinya teman bergaul tidak berpengaruh langsung terhadap IPK. Sedangkan pengaruh tidak langsung antara variabel teman bergaul dengan IPK dalam artian melalui mediasi (intensitas belajar) sebesar 0,174. Penelitian ini membantah penelitian sebelumnya yang dilakukan oleh Singgih Tego Saputro dan Pardiman15. Pada penelitian terdahulu diperoleh hasil yang signifikan antara pengaruh teman bergaul terhadap prestasi belajar yaitu sebesar 18,4\%. Penelitian ini juga membantah penelitian yang dilakukan oleh

12 Slameto, Belajar Dan Faktor Yang Mempengaruhinya.

13 Suratno Suratno, "Pengaruh Lingkungan Keluarga Dan Lingkungan Pergaulan Terhadap Prestasi Belajar Ekonomi Siswa Kelas XI IPS SMA Negeri 3 Kota Jambi Tahun 2012/2013," Jurnal Tekno-Pedagogi 4, no. 1 (2014), https://onlinejournal.unja.ac.id/pedagogi/article/view/2249.

14 Tulus Tu'u, Peran Disiplin Pada Perilaku Dan Prestasi Siswa (Jakarta: Rineka Cipta, 2004).

15 Singgih Tego Saputro and Pardiman Pardiman, "Pengaruh Disiplin Belajar Dan Lingkungan Teman Sebaya Terhadap Prestasi Belajar Mahasiswa Program Studi Pendidikan Akuntansi Angkatan 2009 Fakultas Ekonomi Universitas Negeri Yogyakarta," Jurnal Pendidikan Akuntansi Indonesia 10, no. 1 (June 1, 2012), https://doi.org/10.21831/jpai.v10i1.923. 
Suratno yang menunjukkan bahwa pengaruh lingkungan pergaulan terhadap prestasi belajar siswa sebesar $12,67 \% 16$.

Hasil penelitian menunjukkan pengaruh variabel intensitas belajar signifikan secara statistik karena memiliki nilai koefisien sebesar 0,598 dan nilai signifikansi sebesar 0,000 $<0,05$ maka Ho ditolak, artinya Intensitas Belajar berpengaruh langsung terhadap IPK. Hasil penelitian ini sejalan dengan penelitian sebelumnya yang dilakukan oleh Ninda Ayu Novitasari17 Terdapat pengaruh antara intensitas belajar dengan hasil belajar siswa. Besarnya pengaruh antara intensitas dengan hasil belajar siswa adalah 0,43 dengan persentase koefisien determinasi sebesar 18,49\%. Hal tersebut berarti 18,49\% hasil belajar dipengaruhi oleh intensitas belajar dan 81,51\% dari faktor lain. Penelitian lainnya yang menguatkan hasil penelitian ini yaitu dilakukan oleh Wahid Mustofa dengan kesimpulan bahwa terdapat pengaruh langsung intensitas belajar terhadap prestasi belajar ${ }^{18}$.

Hasil uji hipotesis menunjukkan terdapat pengaruh tidak langsung yaitu dari variabel dukungan keluarga terhadap IPK mahasiswa melalui variabel intervening yaitu intensitas belajar. Besar pengaruh tidak langsung dukungan keluarga terhadap IPK yaitu sebesar 0,006. Hasil penelitian menunjukkan terdapat pengaruh tidak langsung dari variabel teman bergaul terhadap IPK mahasiswa melalui variabel interveningyaitu intensitas belajar. Besar pengaruh tidak langsung dukungan keluarga terhadap IPK yaitu sebesar 0,015 .

\section{Kesimpulan}

Berdasarkan hasil penelitian dan pembahasan seperti yang diuraikan di atas, maka dapat disimpulkan bahwa dukungan keluarga dan teman bergaul berpengaruh secara tidak tidak langsung terhadap IPK melalui intensitas belajar sebagai variabel interverning.

Bagi orang tua sebaiknya jika memungkinkan secara rutin menanyakan perkembangan perkuliahan anaknya meskipun hanya dengan pertanyaan sederhana. Hal ini penting agar anak memiliki motivasi lebih dalam mengikuti proses perkuliahan. Dukungan keluarga, khususnya orang tua

16 Suratno, "Pengaruh Lingkungan Keluarga Dan Lingkungan Pergaulan Terhadap Prestasi Belajar Ekonomi Siswa Kelas XI IPS SMA Negeri 3 Kota Jambi Tahun 2012/2013."

17 Ninda Ayu Novitasari, "Pengaruh Intensitas Belajar Terhadap Hasil Belajar Siswa Kelas V Di SD Gugus Terampil Kecamatan Secang Kabupaten Magelang” (PhD Thesis, Universitas Negeri Semarang, 2016).

18 Wahid Mustofa, "Pengaruh Suasana Belajar Dan Motivasi Belajar Terhadap Intensitas Belajar Serta Dampaknya Pada Prestasi Belajar Matematika," Skripsi Sarjana Tidak Diterbitkan. Surakarta: FKIP UMS [Fakultas Keguruan Dan IImu Pendidikan, Universitas Muhammadiyah Surakarta]. Tersedia Secara Online Juga Di: Http://Eprints. Ums. Ac. Id/31446/13/NASKAH_PUBLIKASI. Pdf [Diakses Di Singaraja, Bali, Indonesia: 19 Desember 2018], 2014. 
yang tinggi pada mahasiswa sangat menentukan terhadap hasil yang diperolehnya sehingga dapat meningkatkan prestasi belajar mahasiswa. Bagi mahasiswa agar bergaul dengan teman yang mampu membimbingnya dalam belajar, saling menasehati saat ada yang terlalai sebab seorang teman mencerminkan pribadi temannya sendiri. Teman bergaul yang baik mampu memberikan pengaruh yang baik pula terhadap hasil belajar seseorang. mahasiswa juga diharapkan agar dapat meningkatkan intensitas belajarnya baik disiplin dalam menjalankan jadwal belajar dengan mempelajari materi sebelum dipelajari di sekolah, disiplin dalam memenuhi waktu belajar yaitu bukan belajar hanya pada saat ada ulangan atau tugas, belajar dapat dilakukan secara terus menerus dan rutin sehingga akan menjadikannya kebiasaan, belajar yang baik, dan disiplin terhadap tanggung jawabnya sebagai seorang pelajar dimana senantiasa belajar saat memiliki waktu luang tanpa paksaan.

\section{Daftar Pustaka}

Daely, Karyanus, Ujian Sinulingga, and Asima Manurung. "Analisis Statistik Faktor-Faktor Yang Mempengaruhi Indeks Prestasi Mahasiswa." Saintia Matematika 1, no. 5 (2013): 483-494.

Dariyo, Agoes. "Psikologi Perkembangan Remaja." Bogor: Ghalia Indonesia, 2004.

Hendikawati, Putriaji. "Analisis Faktor Yang Mempengaruhi Indeks Prestasi Mahasiswa." Kreano, Jurnal Matematika Kreatif-Inovatif2, no. 1 (2011): 27-35.

Levine, Debra Siegel, Robert Joseph Taylor, Ann W. Nguyen, Linda M. Chatters, and Joseph A. Himle. "Family and Friendship Informal Support Networks and Social Anxiety Disorder Among African Americans and Black Caribbeans." Social Psychiatry and Psychiatric Epidemiology 50, no. 7 (2015): 1121-1133.

Melda. "Pengaruh Media Massa Terhadap Intensitas Belajar Matematika Di Rumah Pada Siswa Kelas XI IPS MAN Palopo." Skripsi, IAIN Palopo, 2015.

Mesas, Arthur E., Paul E. Peppard, Lauren Hale, Elliot M. Friedman, F. Javier Nieto, and Erika W. Hagen. "Individuals' Perceptions of Social Support from Family and Friends Are Associated with Lower Risk of Sleep Complaints and Short Sleep Duration." Sleep Health 6, no. 1 (2020): 110-116.

Mustofa, Wahid. "Pengaruh Suasana Belajar Dan Motivasi Belajar Terhadap Intensitas Belajar Serta Dampaknya Pada Prestasi Belajar Matematika." Skripsi Sarjana Tidak Diterbitkan. Surakarta: FKIP UMS [Fakultas Keguruan Dan IImu Pendidikan, Universitas Muhammadiyah Surakarta]. Tersedia Secara Online Juga Di: Http://Eprints. Ums. Ac. Id/31446/13/NASKAH_PUBLIKASI. Pdf [Diakses Di Singaraja, Bali, Indonesia: 19 Desember 2018], 2014. 
Novitasari, Ninda Ayu. "Pengaruh Intensitas Belajar Terhadap Hasil Belajar Siswa Kelas V Di SD Gugus Terampil Kecamatan Secang Kabupaten Magelang." PhD Thesis, Universitas Negeri Semarang, 2016.

Oriol, Xavier, Javier Torres, Rafael Miranda, Marian Bilbao, and Harry Ortúzar. "Comparing Family, Friends and Satisfaction with School Experience as Predictors of Swb in Children Who Have and Have Not Made the Transition to Middle School in Different Countries." Children and Youth Services Review 80 (2017): 149-156.

Patty, Salomina, Sutarto Wijono, and Adi Setiawan. "Hubungan Dukungan Sosial Teman Sebaya, Kontrol Diri, Dan Jenis Kelamin Dengan Prestasi Belajar Siswa Di SMA Kristen YPKPM Ambon." PSIKODIMENSIA 15 (June 20, 2017): 204. https://doi.org/10.24167/psiko.v15i2.989.

Pepe, Kadir. "A Research of the Relationship Between Study Skills of Students and Their Gpa." Procedia-Social and Behavioral Sciences 47 (2012): 1048-1057.

Saputro, Singgih Tego, and Pardiman Pardiman. "Pengaruh Disiplin Belajar Dan Lingkungan Teman Sebaya Terhadap Prestasi Belajar Mahasiswa Program Studi Pendidikan Akuntansi Angkatan 2009 Fakultas Ekonomi Universitas Negeri Yogyakarta." Jurnal Pendidikan Akuntansi Indonesia 10, no. 1 (June 1, 2012). https://doi.org/10.21831/jpai.v10i1.923.

Slameto. Belajar Dan Faktor Yang Mempengaruhinya. Jakarta: Rineka Cipta, 2010.

Sri Wahyuni, Putri. "Pengaruh Intensitas Belajar, Kemampuan Berpikir Kritis Dan Cara Belajar Terhadap Prestasi Akademik Mahasiswa Pada Program Studi Pendidikan Ekonomi STKIP PGRI Sumatera Barat." PhD Thesis, STKIP PGRI SUMATERA BARAT, 2016.

Suratno, Suratno. "Pengaruh Lingkungan Keluarga Dan Lingkungan Pergaulan Terhadap Prestasi Belajar Ekonomi Siswa Kelas XI IPS SMA Negeri 3 Kota Jambi Tahun 2012/2013." Jurnal Tekno-Pedagogi 4, no. 1 (2014). https://online-journal.unja.ac.id/pedagogi/article/view/2249.

Tu'u, Tulus. Peran Disiplin Pada Perilaku Dan Prestasi Siswa. Jakarta: Rineka Cipta, 2004. 